ELENA

GARCÍA-OLIVEROS
Investirgadora independiente elena.free@gmail.com

\title{
Prácticas sociales en el arte en la ciudad de Madrid: intervención con colectivos vulnerables
}




\section{SOCIAL PRACTICES IN ART IN THE CITY OF MADRID: INTERVENTION WITH VULNERABLE COLLECTIVES}

\section{ABSTRACT}

As of two cases in this study which were carried out in Madrid as social practices in art, community methodologies have been detailed as practiced in order to formalize collaborative creation proposed by each one. El Beso (The Kiss) (2018) and Cuentos que nunca cuentan (Tales that are never told) (2010) were carried out by the artist Toxic Lesbian with the participation of institutions such as Medialab-Prado and Intermediae, both of which are integrated in Matadero Madrid, Contemporary art creation center of the City Hall of Madrid. Both cases involved participation of the most directly concerned audiences because of the themes undertaken: migrant women in El Beso (The Kiss) and collectives of directly involved people in mental health in Cuentos que Nunca Cuentan (Tales that are never told). The proposals presupposed intervention in the public space of the city for their production and involved a wide representation of activists and elements of social or cultural institutions. This qualitative análisis of the processes and testimonies of the agents that participated seeks delving into the motivations of communities to become involved in this type of development, the role played by institutions or the inevitable politization of the proposals by the administrative structures that finance them.

\section{Keywords}

New genre of public art; communitarian art; mental health; gender and migration

\section{RESUMEN}

A partir de dos casos, objetos de este estudio, y desarrollados en la ciudad de Madrid como prácticas sociales en el arte, se pormenoriza en sus metodologías comunitarias puestas en práctica para formalizar la creación colaborativa que cada uno propone. El Beso (2018) y Cuentos que nunca cuentan (2010) fueron llevados a cabo por la artista Toxic Lesbian con la participación de instituciones como Medialab-Prado e Intermediae, ambas integradas en Matadero Madrid, Centro de creación contemporánea del ayuntamiento. Los dos casos supusieron la participación de los públicos más directamente concernidos por las temáticas abordadas: mujeres migrantes en El Beso y colectivos en primera persona en salud mental para Cuentos que nunca cuentan. Las propuestas presuponían la intervención en el espacio público de la ciudad para su producción, e implicaron a una amplia representación de la sociedad civil a través de asociaciones, activistas y dispositivos institucionales sociales o culturales. Este análisis cualitativo de los procesos y testimonios de los agentes intervinientes persigue profundizar en las motivaciones de las comunidades para implicarse en estos desarrollos, en el papel de las instituciones o en la irremediable politización de las propuestas por parte de las estructuras administrativas que los financian.

\section{Palabras clave}

Nuevo género de arte público; arte comunitario; salud mental; género y migración 


\section{INTRODUCCIÓN}

En el periodo de una década, la segunda del siglo XXI, el Ayuntamiento de Madrid potenció en el seno de sus instituciones artísticas y culturales proyectos de intervención social desde la producción artística. Centros de innovación y creación como Intermediae o Medialab-Prado con el paraguas de Matadero y dependientes del área de cultura de la administración local de la ciudad, disponían de amplios márgenes de actuación y sus programadores tenían claras las prioridades respecto al cómo gestionar estas entidades. Profesionales como Zoe López Mediero desde Intermediae lo circunscribe a lo que denomina "el asalto a las instituciones" en términos de un "rescate a los espacios públicos", mientras que Marcos García en Medialab-Prado apela a la importancia de participar desde la cultura en la vida pública.

Esta intervención directa que hace protagonistas a los públicos, acerca a los artistas a la ciudadanía abriendo procesos colaborativos o facilita la gestión del espacio público como corresponsabilidad social apelando a agentes diversos comprometidos con el procomún ${ }^{1}$, son algunas de las ideas que vertebrarán programas a los que se vincularán un perfil diferente de creadores. Para este análisis recogemos testimonios directos de estos gestores culturales donde exponen el calado de los nuevos programas en sus instituciones con el objeto de ofrecer el marco al estudio posterior sobre metodologías, procesos y resultados obtenidos por dos propuestas artísticas formuladas desde estos contextos.

El Beso (2018) y Cuentos que nunca cuentan (2010) fueron llevados a cabo por la artista Toxic Lesbian², el primero como parte del programa de Intermediae Imagina Madrid ${ }^{3}$ y el segundo para inaugurar la entonces nueva fachada digital de Medialab-Prado. Ambos proyectos se inscriben en el medio de las prácticas sociales en el arte, desde una perspectiva de género y de orientación sexual además en el caso del segundo, y significaron para su desarrollo la participación de una ciudadanía que representaba a esta sociedad civil a la que las temáticas abordadas concernían. Igualmente, y como parte de la formulación de los programas de las instituciones que los acogieron, significaron un modelo de intervención en el espacio público desde estos grupos sociales como parte de la creación colaborativa abierta por la artista. En esta investigación se analizarán ambas obras a partir de la extensa documentación escrita y audiovisual que manejaron.

La metodología seguida por el estudio aborda dos vertientes, por tanto: la primera, el estado de la cuestión acerca de la posición de las instituciones en la gestación de programas y producción de proyectos colaborativos. Entronca ésta en el análisis historiográfico que nos sitúa el origen y desarrollo hasta el momento de este modelo de intervención en el espacio público, un formato que implica la ruptura con el papel tradicional del museo o el centro de arte. La segunda vertiente de estudio nos ofrece un acercamiento a los dos casos mencionados más arriba que ilustran concreciones de estas políticas culturales, y cómo son acogidas por artistas y sociedad civil.

Este artículo tiene por objeto, en definitiva, el conectar los planteamientos de la institución con los procesos artísticos, dando a conocer las claves de la complejidad social que significan. Igualmente, el detallar las implicaciones de formular la colaboración hacia colectivos vulnerables como lo fueron el de mujeres migrantes y racializadas en el caso de El Beso y personas afectadas por un problema de salud mental en Cuentos que nunca cuentan. El punto de vista del artista como observador de la realidad poliédrica que implican estas prácticas sociales en el arte es la 
perspectiva de este análisis, ofreciéndonos los paisajes urbanos que se producen en el tiempo de la mano de estas singulares y fértiles colaboraciones.

\section{LOS FRUTOS DE LA CRÍTICA INSTITUCIONAL}

En los años 80 surge el término de crítica institucional en relación con la tradición conceptual, los procesos de desmaterialización del arte a los que ya aludía muy anteriormente Lucy Lippard (1968), la conexión desde esas mismas fechas de los activismos con los artistas y que esta autora (1983) ilustra extensamente en su bibliografía e igualmente con la nueva orientación de artistas menos representados en los centros expositivos -como las mujeres, racializados o disidencias sexuales- hacia un éxodo de estas instituciones (Suzanne Lacy, 1995). La artista norteamericana Andrea Fraser (Figura 1) es la primera en acuñar el término para referirse a aquellas obras que hacían aflorar el funcionamiento de las instituciones culturales poniendo al descubierto las jerarquías de poder y conflictos que subyacen al mundo del arte.

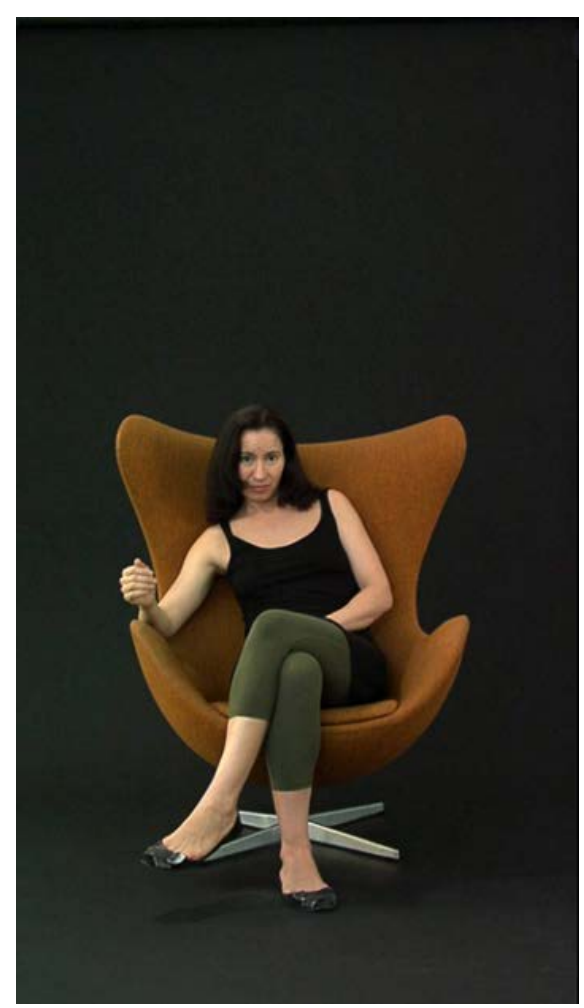

Figura 1. Andrea Fraser, Projections, 2008.

Fuente: https://muac.unam.mx/assets/docs/P-105-Folio_MUAC_048_Andrea_FraserInteriores-72dpi.pdf

Paloma Blanco (2005) alude a la realidad española identificando puntos de conexión con lo aquí mencionado. Esta autora profundiza en el análisis del panorama nacional, donde se fragua una institucionalización del arte oficial representado por las galerías de arte, los macromuseos o ferias comerciales de nuevo cuño en aquel momento como ARCO y que, prosigue, serían 
instrumento de un emergente poder social y político que comienza a instalarse tras la transición democrática y a definirse como Status quo. Este incipiente sistema pretendería toda una compleja operación de simulacro para vender otra cara de España, modernizada y en consonancia con los nuevos contextos en los que pretendería ubicarse, más allá de nuestras fronteras, dirigido a dibujar una identidad más filoeuropea que propiciase nuestra entrada en el selecto grupo comunitario lo más rápidamente posible. Para Blanco el arte colaborativo conecta con un arte politizado que se instaura como alter ego a esta tendencia antojadiza que, a finales de los años 80 y los años 90 , harán del arte visible un producto maleable, adecuado a este mercado. EI movimiento de contracultura definido por estos circuitos de creación colaborativa procura por el contrario una organización autónoma, sin vincularse con estos propósitos capitalistas dominantes. Precisamente la transgresión de las normas sociales en todos sus aspectos es una constante que subyace al arte queer como podemos descubrir en el recopilatorio de 125 años de manifestaciones en esta línea que ilustran Lord y Meyer (2013). Como nos exponen estos autores, la persistente negociación con la invisibilidad y el estigma que afecta a estos grupos sociales, conduce a un modelo de prácticas que, como vemos en este marco y para los ejemplos aquí tratados, se sitúa claramente en la disidencia. En este caso esta disidencia se focaliza referida a las metodologías de creación y al cuestionamiento de las 3 patas del denominado arte elevado -autoría y papel del artista, lo que se ha dado por llamar la 'obra de arte' y el papel de sus públicos-. La cultura queer, prosiguen, presupone una reescritura de los límites del 'arte' y lo que cuenta como tal en la historia, así como entre la alta y la baja cultura. Evidentemente la voluntaria inclusión del proyecto de Toxic Lesbian en estos márgenes que propicia la crítica institucional, asociándose a esta contracultura, conecta con esta sensibilidad, en franco rechazo al marco descrito por Lord y Meyer: la normatividad heteropatriarcal, también significada en el muy convencional medio del arte.

Los gestores culturales a los que nos referimos más arriba y que hacen posible en España, y más concretamente en Madrid, un cambio real en las instituciones, se hacen eco de esta tradición que estamos describiendo y a la que Fraser pone nombre, como señala López Mediero (s.f.). Casilda Cabrerizo, quien participaría en la coordinación del programa de Imagina Madrid y Azucena Klett, gestora cultural en Intermediae y asesora del Ayuntamiento de Madrid durante la legislatura de Manuela Carmena, exponen (2015) de qué modo conectará la cultura con la participación política por el cambio en esta ciudad, apuntando ya a cómo el arte inmerso en estos paradigmas devendrá un arte politizado.

Para Klett y López Mediero (2021) los proyectos que se desarrollan desde este enfoque tienen un papel esencial como también el de las comunidades que le dan cuerpo en la redefinición del espacio público. Considera que, en los procesos abiertos por sus propuestas, se contemplan claramente las grietas producidas por una administración que va por detrás de los modos de habitar, de tal modo que el arte se torna ese ecosistema que hace posible la experimentación desde su radicalidad. En este sentido aprecia cómo la institución cultural interpela a la clase dirigente abriendo preguntas respecto a su dimensión legislativa.

En 2020, culminado el cambio de signo político en la alcaldía de Madrid, y después de desprogramar el Centro de creación contemporánea Matadero la segunda edición de la que sería probablemente la iniciativa que mejor reflejaría su modelo de cambio: Imagina Madrid, Klett y López Mediero se expresan en términos de "producir cultura experimental y comunitaria", explicando su gestión como programas de acción situada en el espacio público en los que va a colaborar una ciudadanía activa. Se distancian en este sentido del tradicional rol pasivo de 
los públicos del arte que asienta una de las tres patas del 'arte elevado': esa necesaria masa expectante que atiende a las grandes exhibiciones planteadas en las instituciones de referencia y que harán del arte un entretenimiento, como ya expusiera Baudrillard (1978). Este autor, refiriéndose al contexto francés, explica de qué modo el popular espacio del centro de arte Pompidou, visitado por las masas en la capital francesa, sería una 'ficción' del entierro de la cultura: un exterior moderno y seductor que alberga un medio crispado de "viejos valores" (p. 76), artilugio para un proceso de lavado mental del visitante.

Estas autoras continúan explicando cómo estos programas como Imagina Madrid, -dentro de los que se formuló El Beso-, fueron experiencias de descentralización, oportunidades para intervenir en algunas zonas vulnerables de la ciudad de Madrid siempre desde el punto de vista de la creación artística. Subrayan la implicación necesaria del tejido activo de cada territorio teniendo como marco determinados espacios a los que definen como híbridos, compartidos por esta ciudadanía con la administración. Efectivamente, y como veremos al concretar el caso de El Beso, estos espacios, -no todos, cabría subrayar, solo aquellos con la suficiente elasticidad como para comprender las propuestas que se llevaban al territorio-, acogieron los procesos y sin su intervención hubiera sido enormemente complejo su desarrollo (Figura 2).

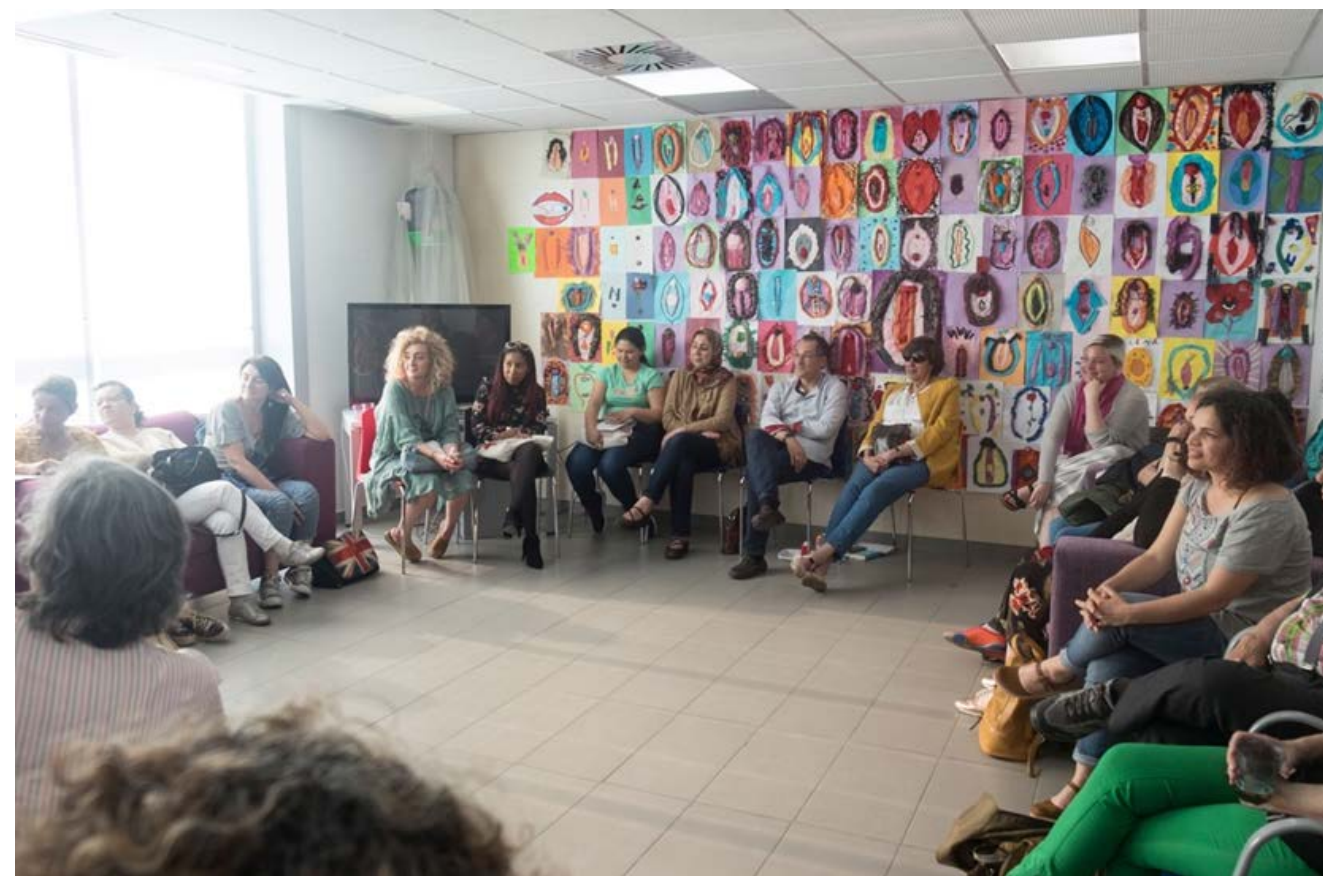

Figura 2. Toxic Lesbian, El Beso, 2018. Reuniones de la comunidad en el dispositivo municipal de igualdad Hermanas Mirabal. Fuente: https://www.toxiclesbian.org/proyectos-de-arte-publico-y-ciberfeminismo/el-beso/

En el caso de Cuentos que nunca cuentan fueron los dispositivos tecnológicos diseñados y construidos por las administraciones como las fachadas digitales (Figura 3) nacionales e internacionales (Figura 4) aquellos en torno a los que se organizó la intervención en el espacio público por parte de las comunidades participantes. El paradigma de colaboración y la función del proyecto en la programación de Medialab-Prado se aleja en este caso de la descrita desde 
Intermediae. El festival de fachadas digitales como evento europeo conectado en el que desembocaría el proceso iniciado a nivel local en Madrid, perseguiría el diseño de grandes eventos tecnologizados donde el compromiso social podría desvirtuarse frente a la noción de espectáculo. Cabe señalar que este dispositivo digital vendría impuesto a la institución desde el área de cultura del ayuntamiento, sin haber sido demandado por la primera, y abriendo la puerta a relacionar su instalación con la ubicación de Medialab-Prado en la 'milla del arte' madrileña -museos Thyssen, Prado, Reina Sofía-.

Oriol Fontdevila (2015) problematiza acerca del cómo la práctica artística colaborativa es vista con suspicacia desde el comisariado por la posibilidad que abre ésta de sortear los mecanismos tradicionales del medio del arte, confrontándola al modo de hacer unidireccional y vertical del comisariado, que responde, afirma Fontdevila, en exclusividad al mundo artístico por su labor legitimadora. Esta función taxonómica se contrapone al proyecto de Intermediae que Fernández, Klett y López Mediero (2015) definen como site-especific alejado de cualquier pretensión de universalidad. Recalcan así estas autoras que se trataría de una institución que más que comisariar es comisariada, redistribuyendo agencias y compartiendo la responsabilidad en la construcción del espacio cultural. Donde Fontdevila describe el áura tutoral del comisariado, Fernández, Klett y López Mediero persiguen espacios de hibridación. Subraya el primero que el papel del museo en los proyectos colaborativos debiera ser ingresar en la madeja de colaboraciones, como un contexto más, y no monopolizando la representación de los resultados de sus procesos. Justo lo contrario de lo que propone Borja-Villel (2012) que como director del Museo Reina Sofía abre la puerta en aquel momento a un nuevo programa con el que esta institución, la de legitimación por autonomasia del 'sistema-arte' español, entraría en la nueva institucionalidad en torno al procomún. Tres medidas cita, esencialmente de archivo y compra para la colección, además de una apertura a la red de colectivos y movimientos sociales que hasta la fecha actual ha sido de corto recorrido y escasa visibilidad más allá de sus muros, todas ellas anunciadas en la revista del museo para, según afirma, replantear la autoridad vertical hacia modos no autoritarios.

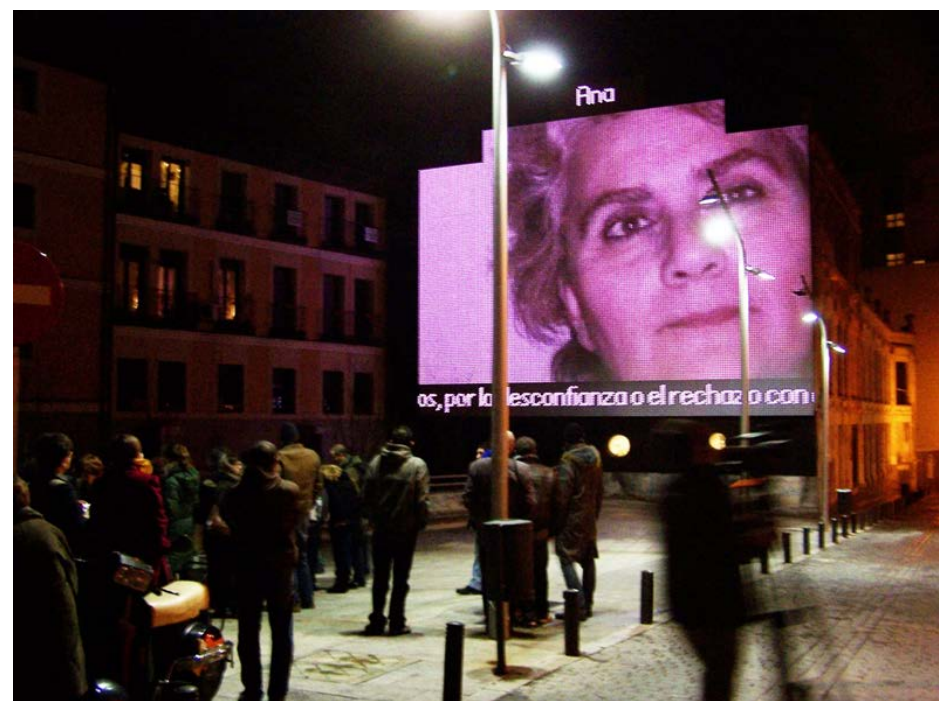

Figura 3. Toxic Lesbian, Cuentos que Nunca Cuentan, 2010.

Intervención en la plaza de la Alameda, Madrid. Fuente: https://www.toxiclesbian.org/proyectos-de-arte-publico-yciberfeminismo/cuentos-que-nunca-cuentan/ 


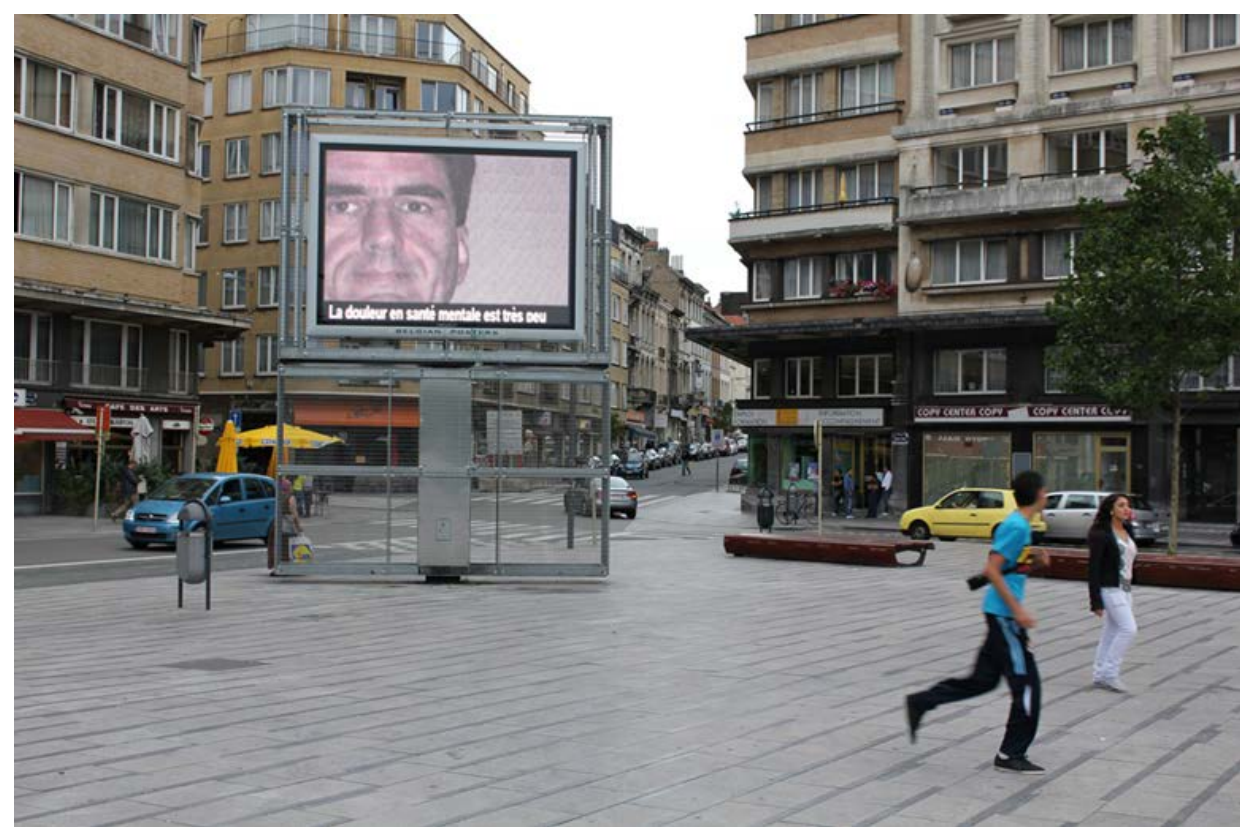

Figura 4. Toxic Lesbian, Cuentos que Nunca Cuentan, 2010.

Fachada digital en Bruselas

Un amplio debate, como vemos, pero que en los inicios de esta tercera década del siglo se vislumbra cómo no despierta en la ciudad de Madrid el interés que aquí queda reflejado, y bien al contrario, el escenario post-apocalíptico provocado por la crisis del COVID-19 encarnizado con la cultura, parece focalizarse tanto hacia las adquisiciones de obra por parte de instituciones, galeristas y coleccionistas para producir de nuevo 'caja' en el sector, como hacia la programación de exhibiciones tradicionales, dejando de lado las importantes inversiones de años anteriores en los procesos del arte comunitario en esta ciudad.

\section{LA EXPERIENCIA POLIÉDRICA DE LA INMERSIÓN EN LAS PRÁCTICAS SOCIALES EN EL ARTE}

Los artistas que trabajan desde los paradigmas del arte colaborativo, comunitario y procesual navegan en estrechos márgenes que, como hemos expuesto, abren su cauce de forma intermitente unas instituciones, las españolas, mucho menos sólidas desde esta perspectiva que las anglosajonas ${ }^{4}$ o de América del Norte $^{5}$ e incluso podríamos citar de otros países del centro y norte de Europa, donde algunos espacios culturales están construidos con la vocación clara de las prácticas sociales en el arte, al margen de lo que el debate político local volublemente quiera hacer de ellas.

Durante la década anterior hemos asistido a programas específicos en la ciudad de Madrid, como hemos visto, que han permitido el desarrollo de experiencias notables, generándose un crecimiento del número de artistas en este campo. La tradición de este modelo de creación tiene sin embargo varias décadas para la historia del arte y en este análisis local nos centramos en aquellas que practican de modo consciente metodologías feministas. La resignificación 
simbólica es, para éstas, primordial en unos proyectos que conectan con la tradición crítica en torno al relato del patriarcado, y buscan producir experiencias estéticas significativas que sitúen a sus públicos en otros paradigmas.

Los dos casos de estudio aquí ofrecidos comparten ese objetivo. Cuentos que nunca cuentan, como explica Toxic Lesbian (2010), pretendía desde esta lectura de género y de orientación sexual contribuir a la visibilización de una parte de la historia de las mujeres y de las lesbianas relacionada con el control psiquiátrico en la sociedad (Figuras 5 y 6 ). Igualmente, y referido a $E I$ Beso, detalla el objeto de la resignificación simbólica del relato de las mujeres como identidades subalternizadas, más aún si cabe al ser éstas mayoritariamente migrantes. La persistencia en el protagonismo de estas identidades menos visibles se relaciona con modelos activistas de creación que situábamos en el marco inicial y que teóricas como Lucy Lippard apoyasen a partir de las primeras convergencias de arte y activismo político en la década de los años 60 . De modo más específico, observamos cómo la perspectiva queer presente en Cuentos que nunca cuentan asoma con la elección como tema de la persecución de los cuerpos lesbianos vía su psiquiatrización. Griselda Pollock (2017), analizando una pieza de las artistas queer Cabello y Carceller, explica cómo las convenciones protegen el orden sociopolítico. Este orden vendría marcado, prosigue, por el partriarcado, el falocentrismo y la heteronormatividad constitutivos de una jerarquía que define el género y se manifiesta de modo asimétrico y represor. La transgresión de los cuerpos, como vemos en la denuncia que los públicos disidentes sexuales participantes en la elaboración de Cuentos que nunca cuentan quieren exponernos, tiene una lógica de castigo que supone la psiquiatrización en el caso del cuerpo feminizado. Esta idea de punitivismo asociado a la ruptura de la representación del género está también estudiada en el caso que Pollock alumbra. Es contra este orden que bien describe esta autora contra el que la obra de Toxic Lesbian se posiciona. Para la artista Suzanne Lacy es también una característica del arte feminista la resistencia a estas prácticas del poder, en este caso manifestadas por la denuncia de la persecución lesbófoba.

Como vemos de modo concreto, estas obras exigen en consecuencia una visión más inclusiva de la sociedad, y en esa búsqueda demandan la participación de las instituciones en la transformación del espacio público en ciudades europeas. Un espacio que no es neutro, sino que, y como nos recuerda Pollock, dispone un funcionamiento normativo que anula y sanciona a sus disidencias frecuentemente. Desde esta perspectiva, vemos cómo estas obras son intrínsecamente políticas desde su formulación, como subrayasen Cabrerizo, Klett y García Bachiller (2015), y cómo de facto proponen otra organización de la calle, otra iconicidad. 


\section{Carmen}

\section{Algunas mujeres}

\section{eligen la fractura}

\section{de la locura}

\section{para ser escuchadas.}

Figura 5. Toxic Lesbian, Cuentos que Nunca Cuentan, 2010.

Testimonio de Carmen

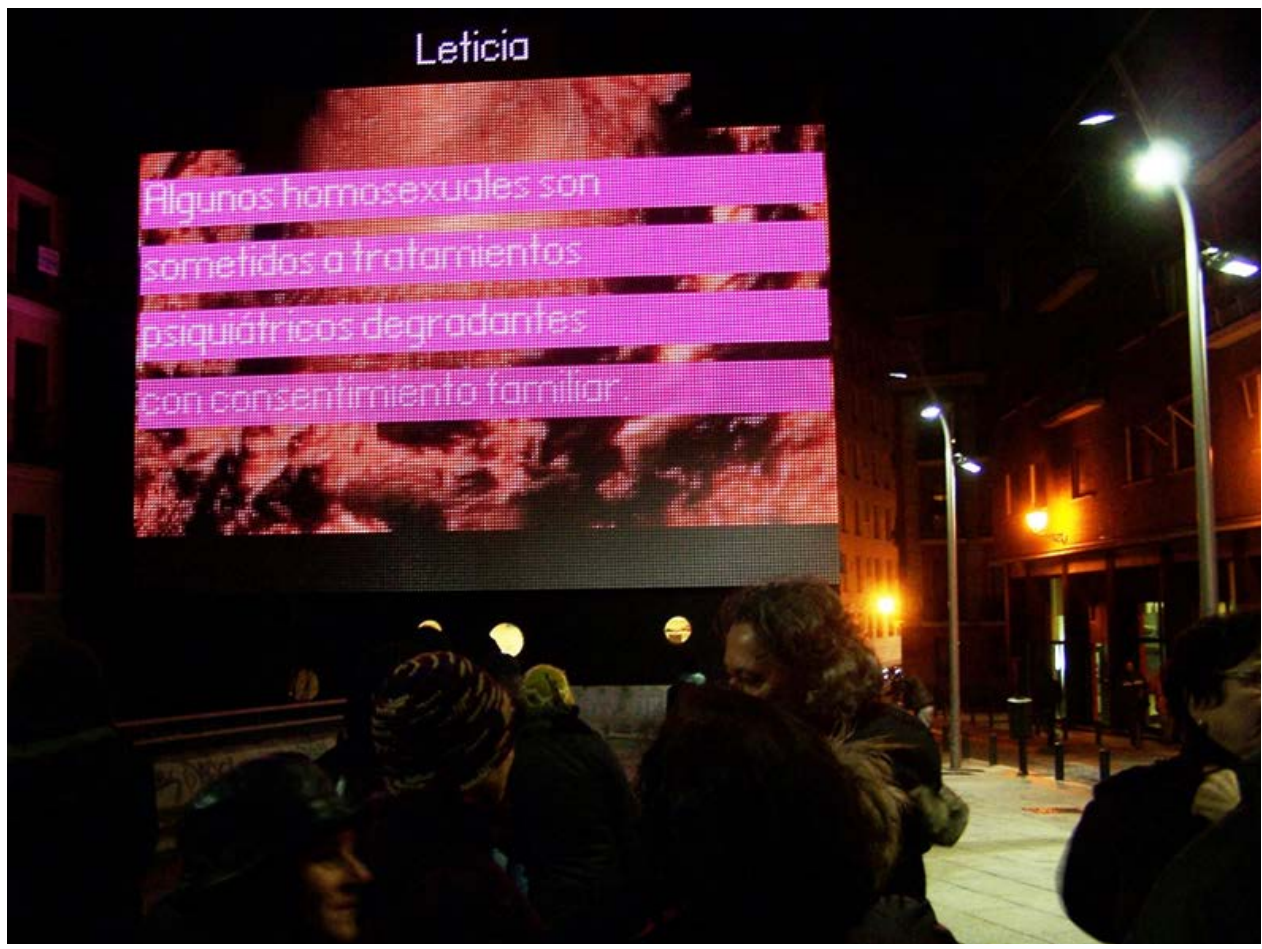

Figura 6. Toxic Lesbian, Cuentos que Nunca Cuentan, 2010.

Testimonio de Leticia en la Plaza de Alameda 


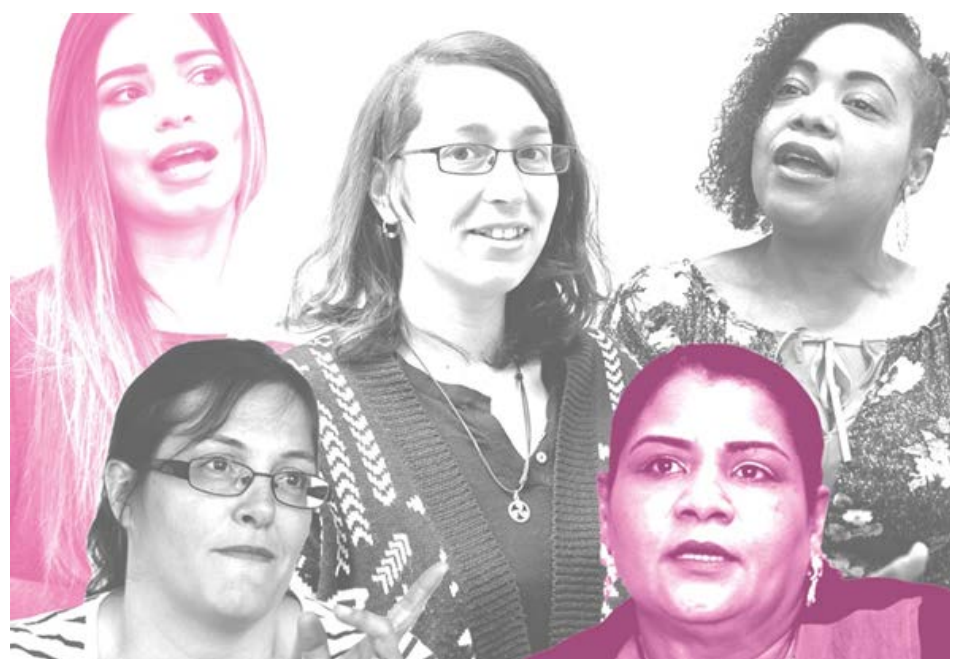

Figura 7. Toxic Lesbian, El Beso, 2018.

Imagen de la comunidad intercultural de mujeres de Tetuán constituida

El modo en que, y en el caso de $E$ I Beso, se otorga ese protagonismo a estas identidades, es construyendo como base metodológica para el desarrollo de esta obra procesual las pedagogías de la escucha de los grupos sociales implicados. Como explica Toxic Lesbian, el proyecto pretende "tejer la relación necesaria para ir al encuentro de la narración en primera persona de emociones vividas en o desde la calle Topete, de los pequeños relatos urbanos que generan la memoria afectiva de toda ciudad". Esta propuesta se va a construir en el distrito madrileño de Tetuán a partir del testimonio de sus vecinas (Figura 8), quienes portan firmes convicciones basadas en rehacer las redes comunitarias, actualmente deterioradas, como garantes de la seguridad y bienestar vecinal. Este aterrizaje es un significado de lo que mencionábamos acerca de cómo estos formatos de creación implican una ruptura con el papel tradicional del centro de arte y cómo son acogidos por sus públicos. Esta sociedad civil se abre a la interlocución con la construcción de la obra y vuelca en ella sus procesos vitales que se constituyen en protagonistas y materia misma de las prácticas artísticas.

Klett y López Mediero justificaban la necesidad de intervenir en estos puntos vulnerables de la ciudad y en su tejido de modo activo para descentralizar el acceso a la cultura y los entornos en los que se produce arte. Esta intención forma parte en sí misma de este nuevo paradigma que mencionamos. El proceso de creación de Toxic Lesbian conecta pues con la formulación desde la gestión cultural. El diseño de la obra ejerce el papel de micropolítica para cubrir la necesidad que las líneas de la institución trazasen. En el caso de Cuentos que nunca cuentan, se desarrolla con la participación comunitaria en procesos de diálogo de personas afectadas, terapeutas, activistas y familiares (Figura 9). Los debates giraban en torno "al estigma de la locura como hecho tabú para la sociedad, rodeado de prejuicios contra la dignidad e instalado en todas las manifestaciones de nuestro entorno que mantiene la creencia de una realidad vergonzante que debe permanecer oculta". Como vemos, la tradición dialógica es pues esencial en la constitución de estas prácticas sociales en el arte, entroncada a los pilares de los feminismos. El Beso y Cuentos que nunca cuentan beben claramente de estas genealogías que se relacionan con una posición del artista como observador participante de la realidad en la que interviene. 


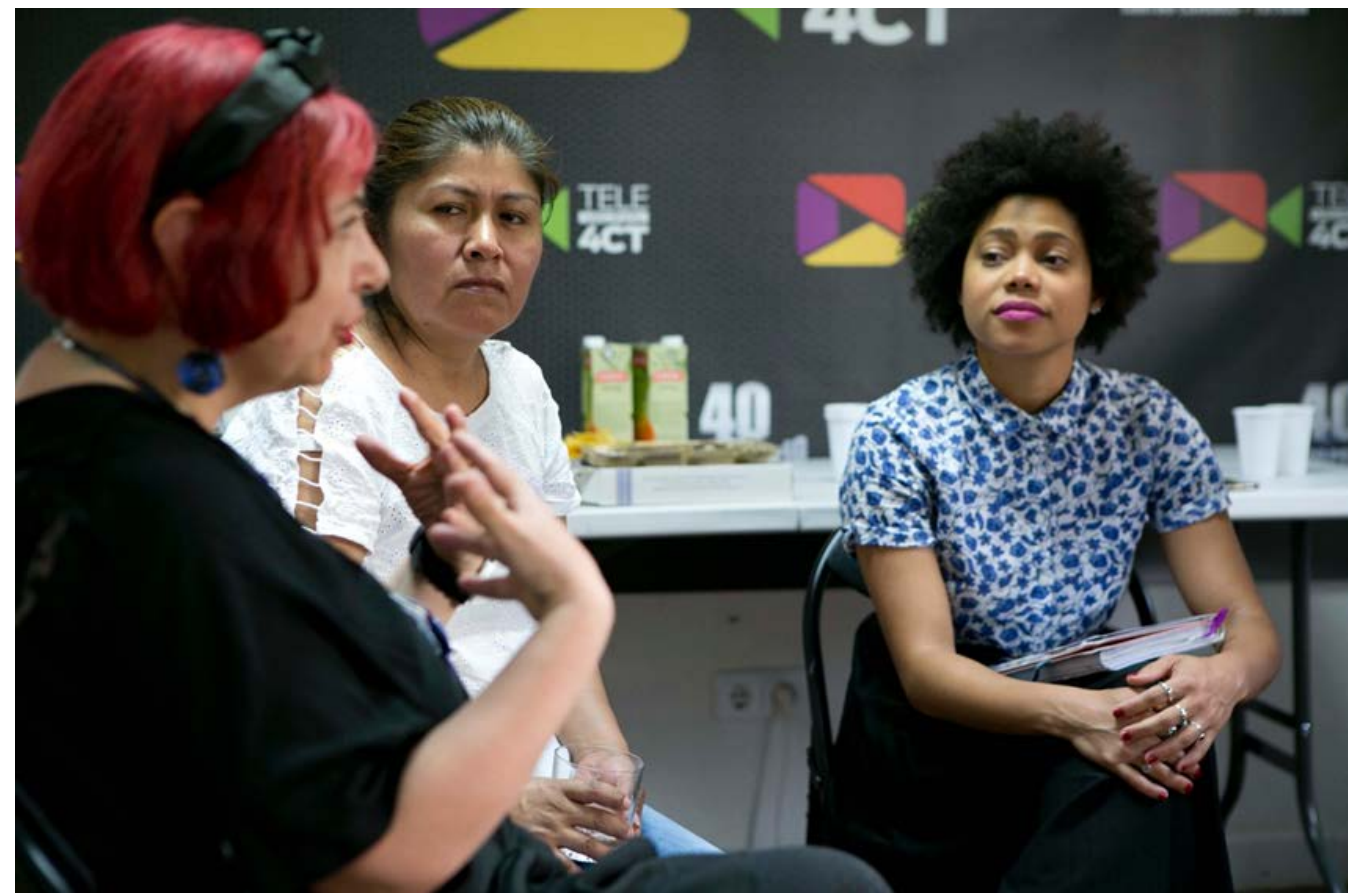

Figura 8. Toxic Lesbian, El Beso, 2018.

Proceso de intervención social del proyecto

El papel de las instituciones madrileñas queda subrayado en las prácticas artísticas de ambos ejemplos, donde las comunidades colaboradoras sienten la necesidad de revertir una realidad que no integra sus aportaciones, que ha desestimado el valor de su participación en la construcción social y que, en mayor o menor medida, prefiere mantenerlos al margen e incluso borrarlos de la toma de decisiones. Para estos grupos sociales la mano de la cultura es, muy probablemente, un alentador aliado para ir a la búsqueda conjuntamente de este objetivo. Señalábamos cómo Fontdevila demanda que la institución entre de modo necesario en esta madeja de colaboraciones para llegar a sus fines, como así ocurre en este marco específico de análisis. Unos fines complejos que responden a la multiplicidad de voces que integran estos desarrollos colaborativos. Precisamente es éste un punto que, como también nos indicara el autor, despierta la lógica legitimadora del comisariado: ¿es esto arte?, ¿es cultura? o ¿es una manifestación puramente social? Citando a Claire Bishop, ahonda en la problemática de que el arte colaborativo llegue a funcionar como arte más allá del lazo social que establece con sus desarrollos. 


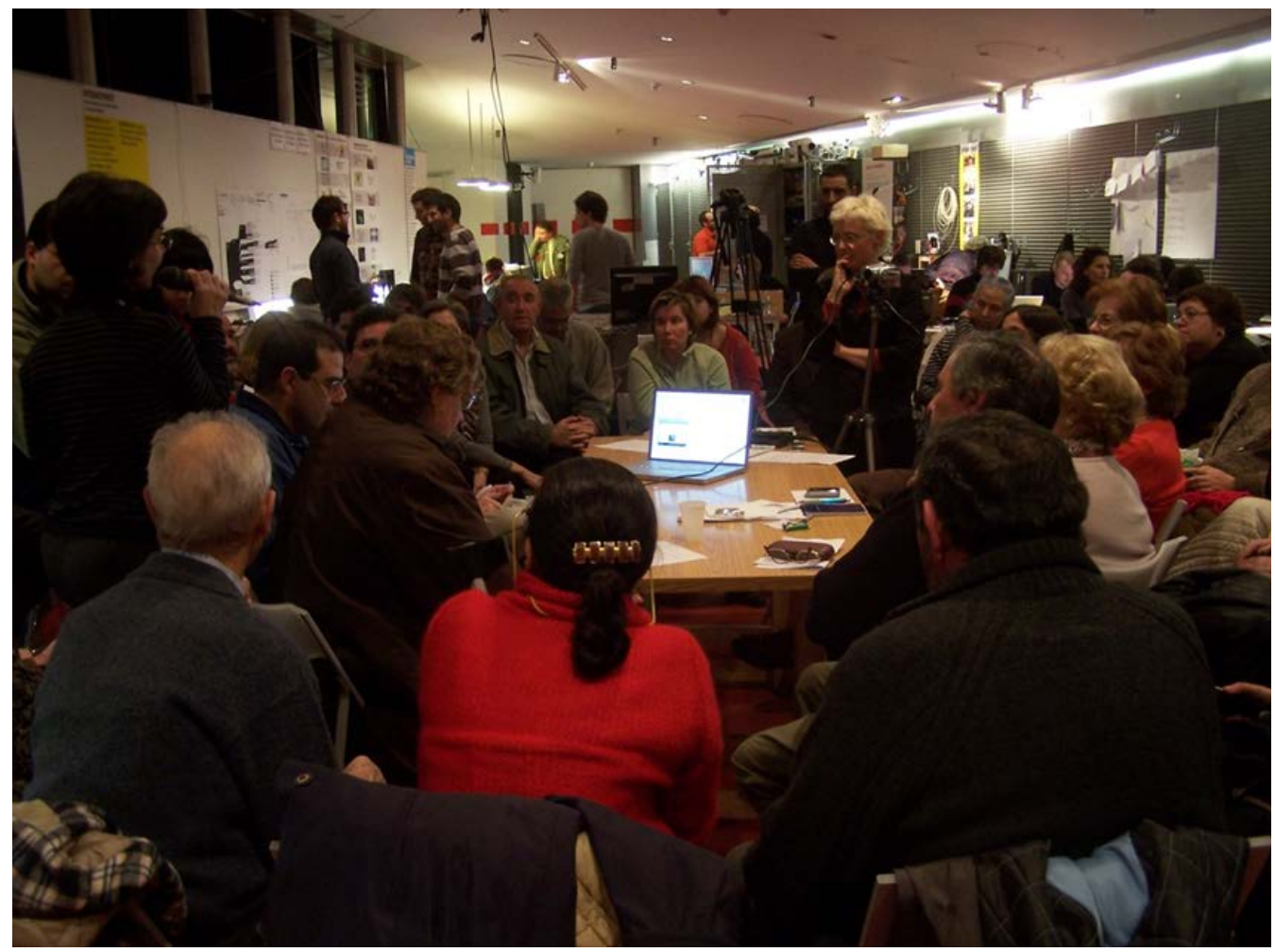

Figura 9. Toxic Lesbian, Cuentos que Nunca Cuentan, 2010.

Diálogos abiertos en Medialab-Prado

Lejos de estos debates jerarquizadores y taxonómicos, los artistas que desarrollan así sus prácticas nos ofrecen otras preocupaciones. Para la formalización de esta escucha activa, necesaria para conseguir la implicación de las comunidades en la experiencia estética, la mediación y los procesos de generación de comunidad se definen como esenciales para hacer realidad la propuesta artística y su concreción final. En el caso de El Beso se contrató a un amplio equipo profesionalizado de mediadoras interculturales, algunas procedentes del terreno y con implantación local, que construyeron vínculos a través de encuentros (Figuras 10 y 11) en la propia calle, en lugares significativos para la comunidad y en el entorno de la institución artística que acogía al proyecto, Matadero, permitiendo paulatinamente la inclusión de algunas de ellas en las piezas colaborativas que se formularon como proceso de creación comunitaria. Como vemos, se trata de un arte autónomo, como lo describiera Blanco, en el sentido de estar al margen de la objetualización final que lo permitiese entrar en una lógica de mercado. Este modo de actuar conecta por tanto con la genealogía de la desmaterialización del arte que citásemos. El arte ya no es un hecho corpóreo sino también esa labor de mediación que en el caso de Cuentos que nunca cuentan se llevó a cabo a través de asociaciones de personas afectadas en salud mental y sus familiares, quienes realizaron a través de ellos mismos, de sus terapeutas y dinamizadores (Figura 12) las convocatorias para asistir a las actividades tanto en Medialab-Prado como igualmente ocupando la vía pública de la ciudad. Estamos claramente ante un arte que no pretende entretener, que se sitúa en otro eje de coordenadas respecto 
a lo que las masas que describiese Baudrillard persiguen. Los círculos concéntricos a los que alude la artista norteamericana Suzanne Lacy -referencia en la construcción del nuevo género de arte público- como modo de organización en torno a la construcción de la obra comunitaria y que configuran los públicos de estas obras, no se podrían definir como masa. Antes bien, se sienten implicados, en mayor o menor medida, y su experiencia estética se constituye en vector de transformación social. Lucy Lippard subraya el rol de motor de cambio de estas prácticas artísticas activistas que aquí también evidenciamos.

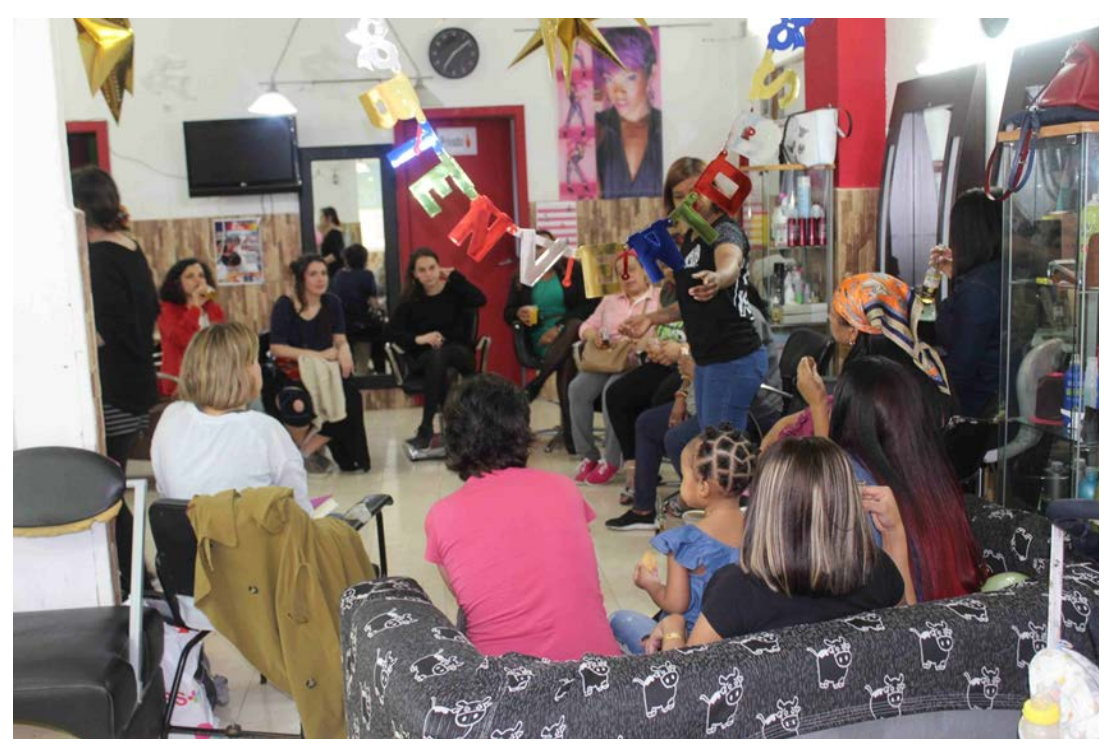

Figura 10. Toxic Lesbian, El Beso, 2018.

Encuentros comunitarios en las peluquerías de la calle Topete de Madrid

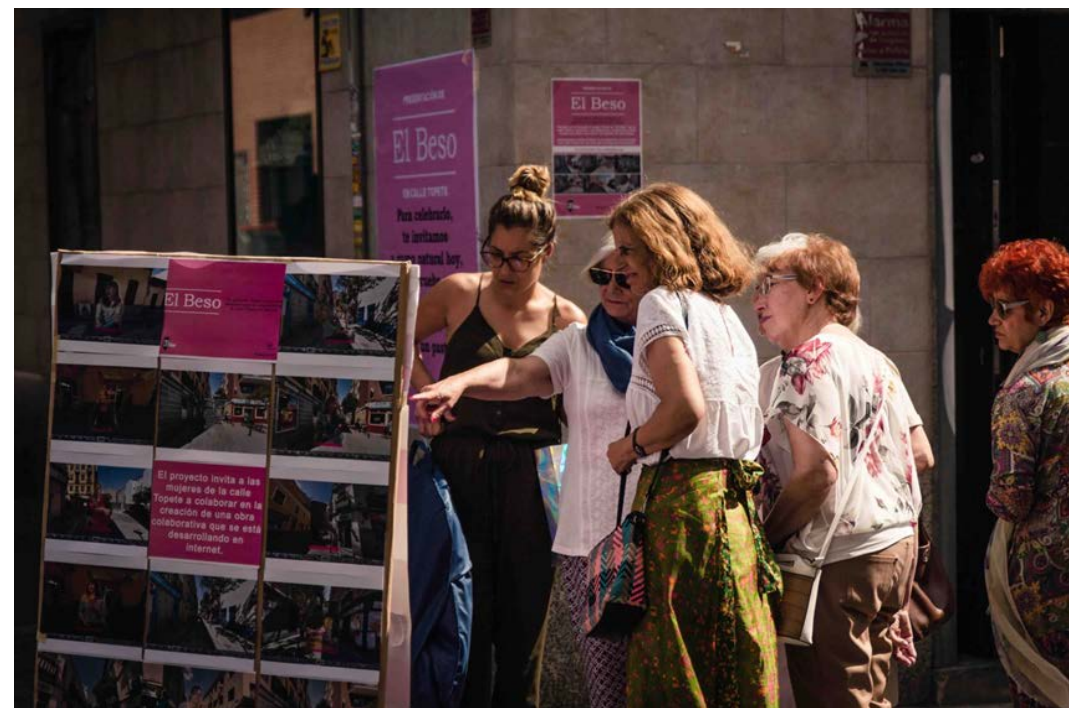

Figura 11. Toxic Lesbian, El Beso, 2018.

Intervención urbana para presentar el desarrollo a la comunidad vecinal 


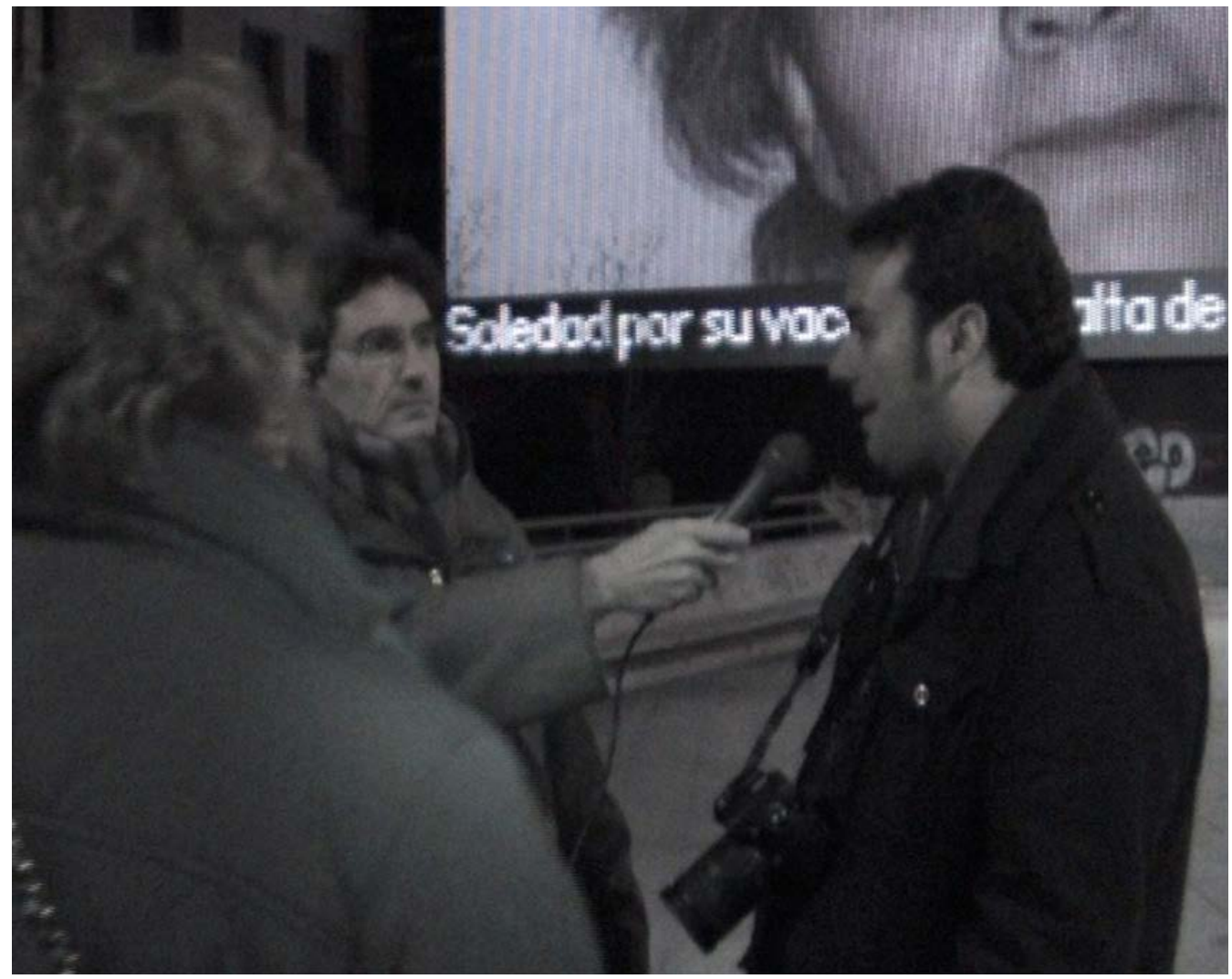

Figura 12. Toxic Lesbian, Cuentos que Nunca Cuentan, 2010.

Dinamización de la escucha realizada por miembros de las asociaciones

Para poder llevar a cabo estos vínculos necesarios para el desarrollo de las propuestas, el papel de las instituciones en uno y otro caso es claramente facilitador, mediando con los marcos normativos para poder interactuar con el espacio urbano. Este aspecto es otra concreción del nuevo papel que se le demanda a la institución cultural. En El Beso con la intervención de la calle Topete a través de sus fachadas, escaparates y balcones que acogieron una selección de obras, muestra de los testimonios de su comunidad (Figuras 13 y 14). O del mismo modo al ocupar fachadas digitales en varias ciudades europeas en Cuentos que nunca cuentan y establecer el diálogo con su ciudadanía con temáticas fuertemente estigmatizadas e invisibilizadas como la de la salud mental (Figuras 15 y 16). Sin esta negociación entre la institución cultural con la clase dirigente que autoriza la realización de estos procesos, con los artistas y sus públicos, su formalización sería inviable, dando cuerpo así como decimos a este otro papel menos convencional del centro de arte o del museo que estudiábamos. Es, efectivamente, como señalasen Fernández, Klett y López Mediero (2015) “una institución que facilita la redistribución de agencias y que enfatiza la responsabilidad compartida en la construcción del espacio cultural". 


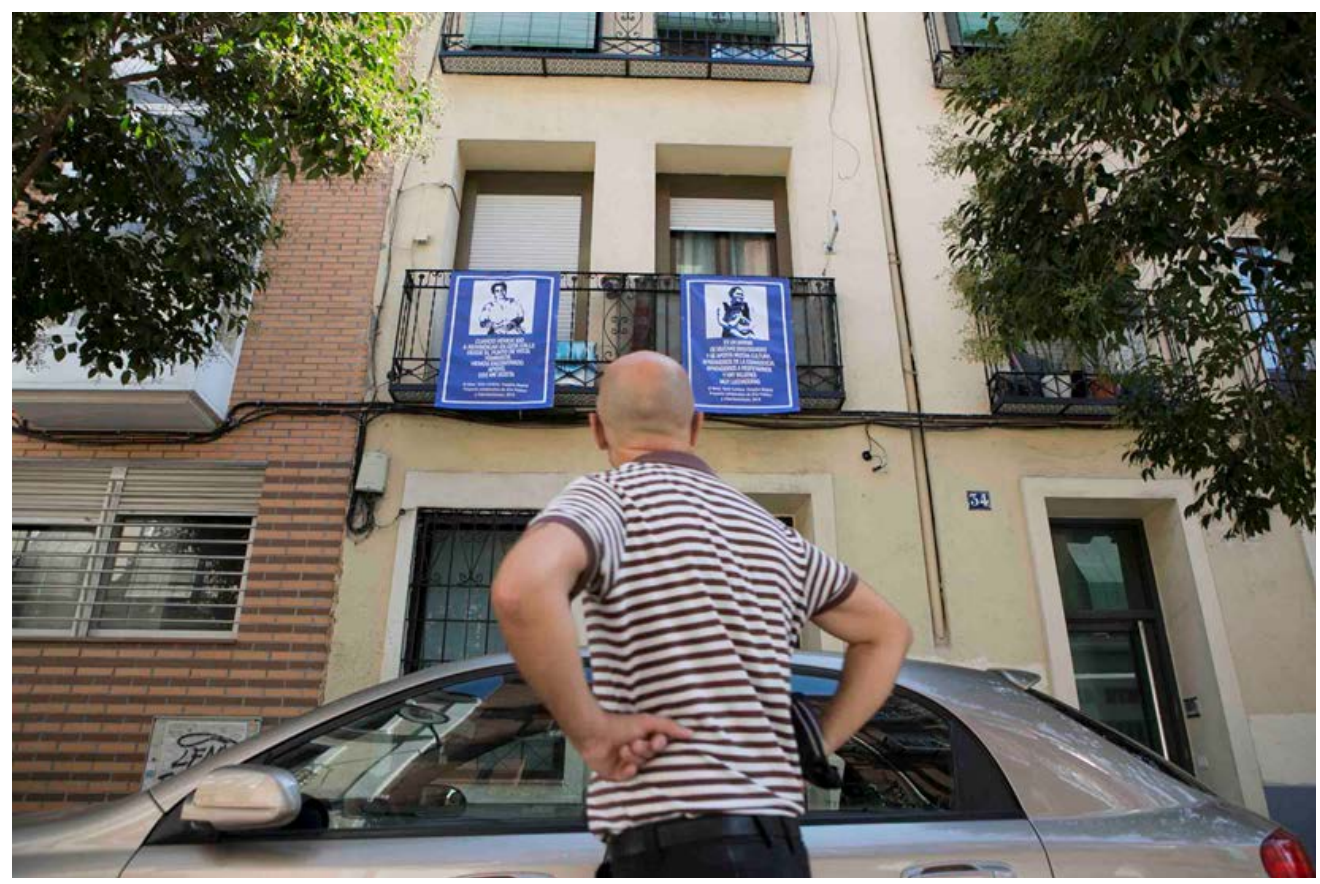

Figura 13. Toxic Lesbian, El Beso, 2018.

Intervención urbana de la exposición de 20 lonas en el distrito de Tetuán

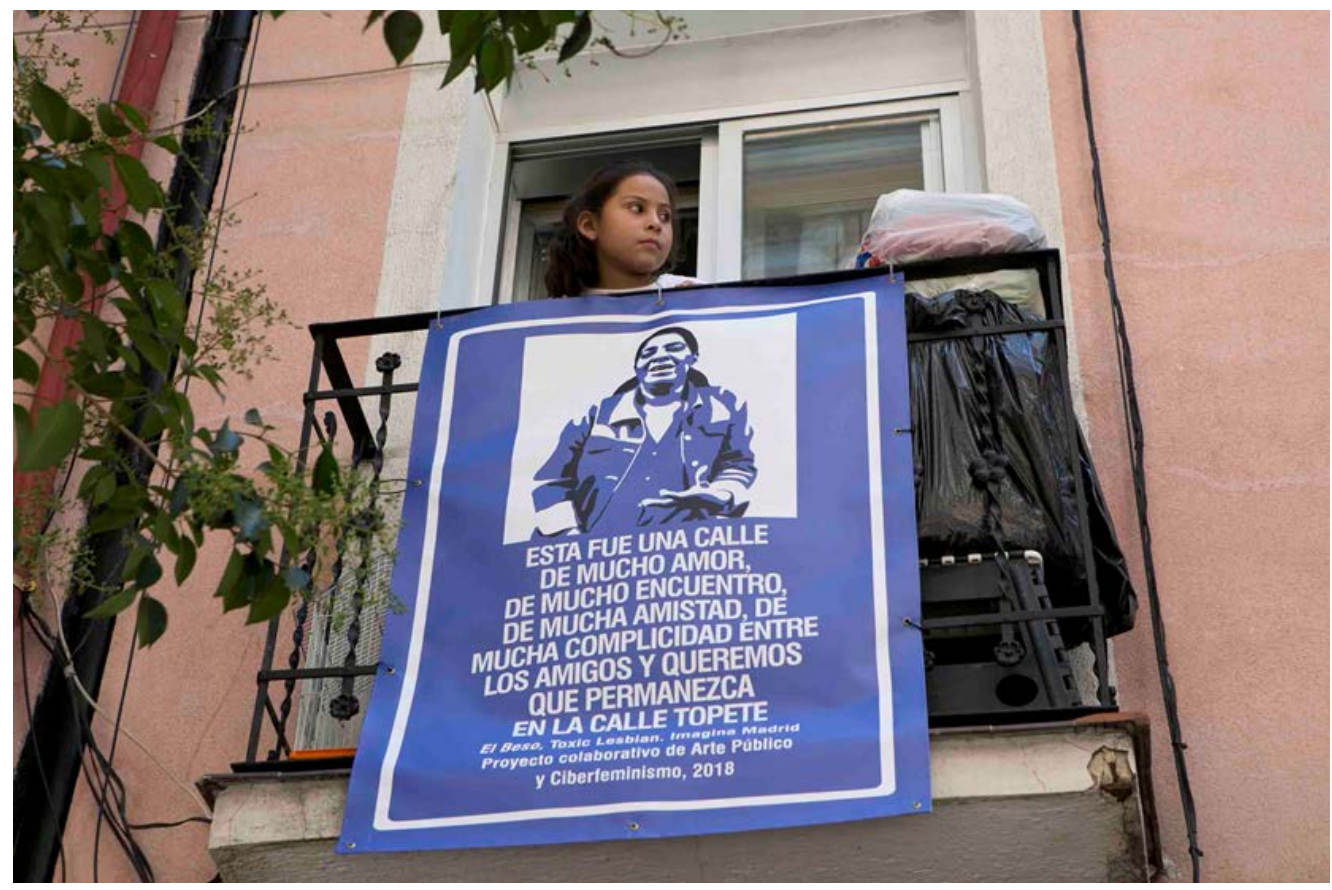

Figura 14. Toxic Lesbian, El Beso, 2018. 


\section{Carmen}

\section{Einige Frauen wählen}

die Verrücktheit als Mittel,

\section{um gehört zu werden}

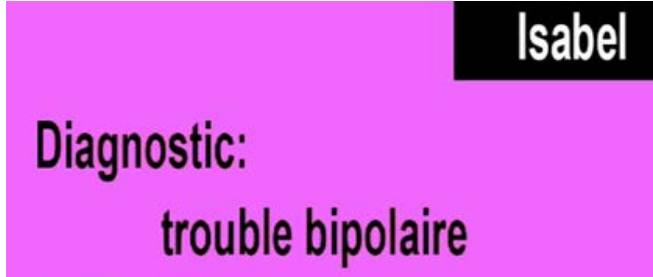

Profession:

activiste social, écrivain

Figura 15 y 16. Toxic Lesbian, Cuentos que Nunca Cuentan, 2010.

El proyecto fue traducido a 4 idiomas para adecuarse a la intervención con las ciudadanías europeas donde fue presentado

Este desarrollo de procesos de creación sostenidos en el tiempo con grupos sociales vulnerables a los que estamos haciendo referencia, es un desafío que se asume desde lo que Fontdevila explica como una colaboración recíproca entre agentes participantes que se saben diferentes. Toxic Lesbian expone cómo la intención del artista: crear, no tiene por qué ser compartida con los públicos participantes y los objetivos que persiguen obedecen en la mayoría de los casos a enunciados desde lo social. El colectivo de mujeres migrantes de El Beso o los de primera persona en salud mental de Cuentos que nunca cuentan son medios sin duda con un interés elevado en ser escuchados y obtener representación simbólica vía la iconografía sofisticada que puede ofrecer el arte. Sin embargo, y como subraya el mismo autor, el espacio urbano no es un entorno idílico y las relaciones de poder entre agentes son un hecho. El trabajo de mediación profesionalizada y representativa del grupo al que se dirige el proceso artístico parece entonces imprescindible para legitimar al artista en el diseño de la experiencia estética. Los proyectos aquí expuestos fueron concebidos con la participación de equipos y organizaciones cuyo papel fue construir esa relación. El equilibrio entre la exposición pública del rol desempeñado por el artista, las comunidades y la institución es complejo, señala Fontdevila. A menudo se produce una sobredimensión de los agentes sociales con el argumento de la necesidad de visibilización, y en otras ocasiones el papel desarrollado por la comunidad no genera un rol subalterno hacia el artista, sino que le da poder, concluye. Es este un elemento de debate esencial en el diseño de los procesos del arte colaborativo, como también lo es, prosigue, el dónde radica el valor de estas prácticas artísticas: en los procesos, en los diálogos, en los vínculos desarrollados o en los productos resultantes.

En esta suma de alianzas y vinculado a los resultados finales obtenidos en materia de creación, no podemos dejar de señalar la producida con la tecnología presente en los dos casos de estudio, en un claro ejemplo de toma de control de este recurso como resistencia desde perspectiva ciberfeminista ${ }^{6}$. El Beso produjo, además de la intervención urbana previamente ilustrada, una pieza netart ${ }^{7}$ (Figuras 17 y 18 ) asociada al funcionamiento de Google maps. En Cuentos que nunca cuentan, los protagonistas de las obras ocupan las grandes dimensiones de las fachadas digitales con su retrato y un breve titular, mientras en internet (Figura 19) y en la calle promueven la participación ciudadana mediante acciones coordinadas. 

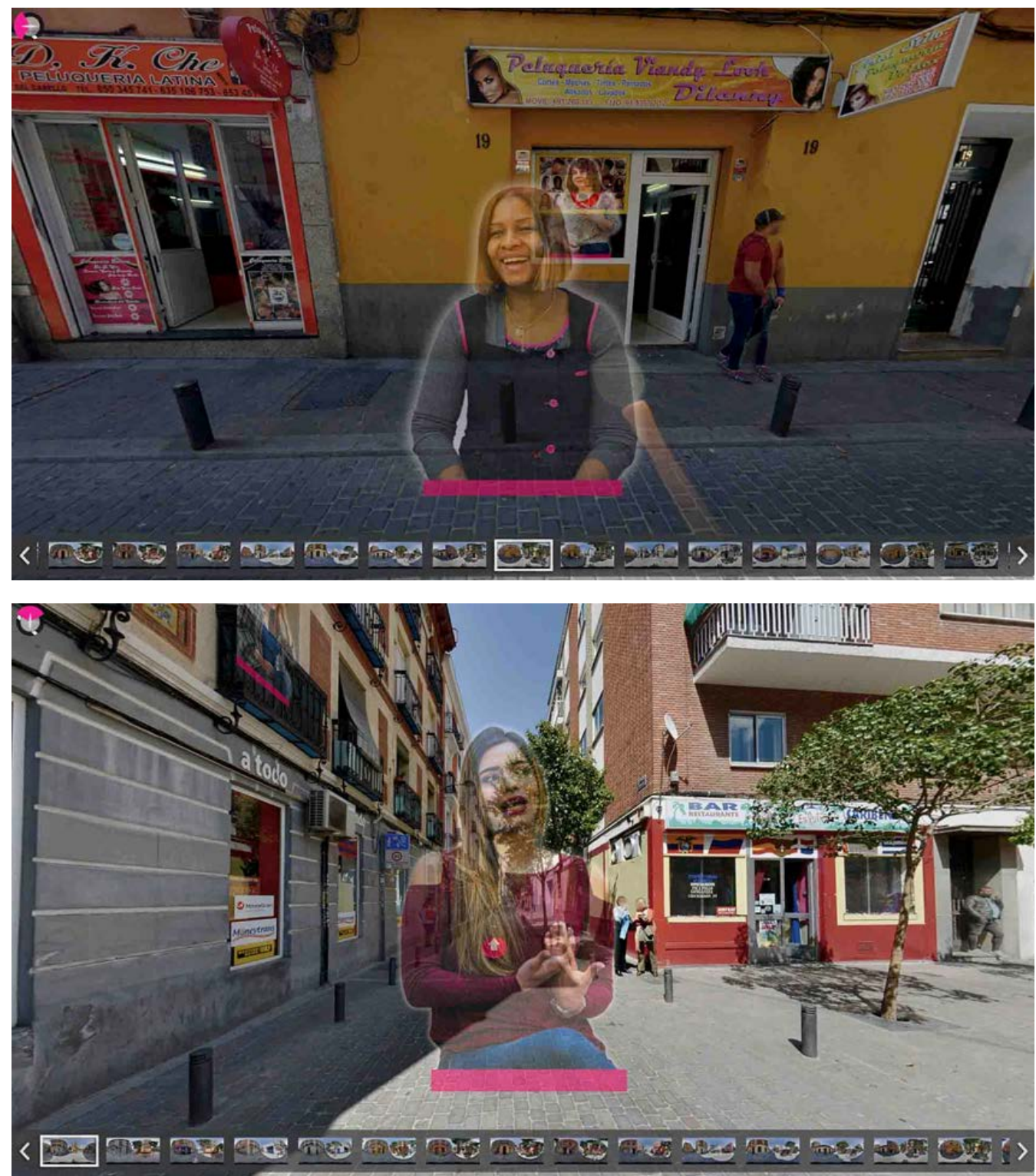

Figura 17 y 18. Toxic Lesbian, El Beso, 2018.

Las mujeres de Tetuán convertidas en ciborgs, realidades virtuales de lo que "podría ser", ocupando el espacio urbano que las invisibiliza 


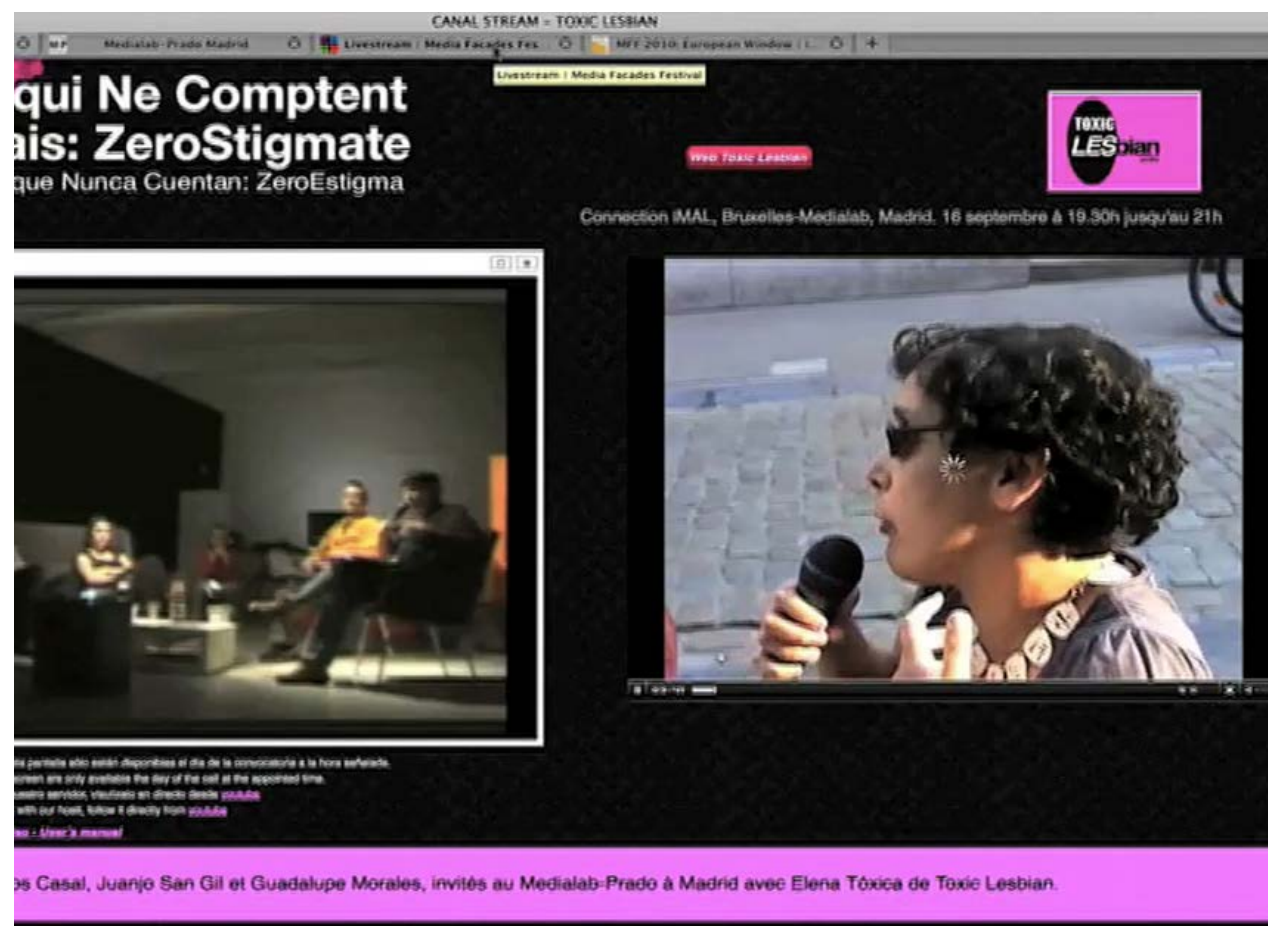

Figura 19. Toxic Lesbian, Cuentos que nunca cuentan, 2010.

Retransmisión en directo de streamings para la Transmediale

Los procesos desarrollados por El Beso y Cuentos que nunca cuentan para la realidad local de la ciudad de Madrid nos sitúan frente a un modelo de creación artística que, como enuncian Fernández, Klett y López Mediero, se ha desvinculado de cualquier pretensión de universalidad. Bien al contrario, se trataría de lo que podríamos denominar un 'arte situado' siguiendo a Haraway (1991b), en la medida en que fundamenta la obra ligada a su contexto, así como a la subjetividad de los grupos sociales con los que se produce. En ambas obras hemos destacado la conexión y generación de comunidades vinculadas con las problemáticas que se exponen en sus propuestas, extraídas del tejido local de la ciudad.

Los paradigmas desde los que se gestan, para el momento y lugar en el que son creadas, redefinen las formas tradicionales de relación entre instituciones artísticas y ciudadanía, de ésta con sus administraciones y a su vez con la implicación de movimientos sociales y activistas, como explican las autoras mencionadas. Son fruto de una voluntad posible que une a todos los agentes en torno a su producción. La concreción a la que dan lugar es exponente de "estos otros métodos, puntos de encuentro y modelos de gobernanza" que citan. Piezas que ocupan posiciones fronterizas y que, como especulan en su texto, se mueven entre el "dentro y fuera" de la institución museística. En este sentido, la suspicacia con la que son miradas por parte del comisariado como agente legitimador, como nos señala Fontdevila, se relacionan con la disolución del rol pasivo de los públicos frente a otro recíproco y horizontal con el artista, que deja, definitivamente, de ser etiquetado como 'genio'. Esta renuncia no es accesoria, sino que 
por el contrario forma parte misma de la idiosincrasia del nuevo género de arte público, como lo nombra Suzanne Lacy, en actitud de clara disidencia respecto al medio convencional del arte. Linda Nochlin ya en 1971 con su texto fundacional de la crítica de arte feminista, presenta en una lúcida exposición el concepto de 'genio' y 'gran artista' en relación con la masculinidad y un determinado punto de vista de la historia del arte no cuestionado en aquel momento, claramente patriarcal. Nochlin desgrana lo que denomina una subestructura romántica y elitista que persigue el encumbramiento de ciertos individuos, en todos los casos hombres cis, blancos, heterosexuales y occidentales. La ruptura con este modo de proceder se inicia no solo con las mujeres artistas sino con otras disidencias como artistas racializados y queer, como hemos mencionado. En los casos estudiados, la artista se somete a los procesos comunitarios: los ritmos de la creación no dependen de su fluir en un taller cerrado sino de múltiples factores que condicionan la evolución del proyecto e incluso su viabilidad. La negociación con estos factores externos es continua y la voz de las comunidades concernidas prioritaria en la construcción de la obra final. Las dos propuestas conectan con colectivos vulnerables por lo que, además, es extremadamente delicado no caer en una violencia epistémica que jerarquice un rol sobre otro.

En el caso de las prácticas sociales en el arte, además, hemos apreciado cómo no se pretende manejar a la institución museística para resignificarlo como arte, como señala Fontdevila, sino que es un agente más en la producción y posibilitación del proyecto. Así, hemos descrito el papel mediador de Intermediae o Medialab-Prado con el contexto político o administrativo. Sin embargo, este mismo autor deja la puerta abierta a la cuestión de si estaríamos frente a procesos que podrían denominarse 'arte' en todos los casos, sosteniendo nuevamente la tensión legitimadora y de poder atribuible al museo. El límite, prosigue, estaría en el balance de la experiencia estética frente a los vínculos creados con el arte colaborativo, debiendo primar nítidamente una lectura completa y comunicable desde el exterior respecto a su impacto estético. Enfatiza igualmente cómo la consideración de arte procesual, dialógico, como lo describe Kester (2013), nos aleja del modelo bancario del mundo del arte. Un sistema por el que se deposita el contenido expresivo en un objeto de carácter único y referencial por parte del creador, de autoría inequívoca, para posteriormente ser 'reembolsado' por el espectador. Por el contrario, el paradigma que nos plantean estas obras se basa en conversaciones, en interacciones entre los participantes quienes van tejiendo, en el tiempo de desarrollo que convienen, la que será la obra, material o no. Este formato de creación no queda definido por tanto por su capacidad expositiva sino por abrir una línea de comunicación entre los agentes y sus públicos, concluye Fontdevila. En El Beso y Cuentos que nunca cuentan los procesos dialógicos tienen un gran protagonismo, así como su archivo y comunicación, pero en ambos casos hay concreción en piezas finales que se vinculan a las prácticas artísticas 'museables'.

El muy estimado marco de la experiencia estética permite el abordaje de problemáticas sociales muy conflictuadas, con colectivos vulnerables y muy estigmatizados como lo son para estos casos de estudio. El lugar de preferencia desde la escucha, con la localización de la sensibilidad inherente a todo proceso creativo, crea unas condiciones a priori óptimas para alcanzar esa ansiada resignificación simbólica que mueve a los grupos sociales participantes. Las metodologías desarrolladas para poder establecer esos vínculos definen y caracterizan a cada artista, generan un estilo en la implementación de los proyectos e incluso, más allá de las obras finales si las hubiere, nos hablan de la identidad creadora. La creencia en el poder de transformación del arte es, para este tipo de propuestas, más evidente por la capacidad de conmover las conciencias que se implican en estos procesos dialógicos, como expone Kester. Para este caso de estudio nos decantamos por el claro valor del arte colaborativo en la línea que propone este autor frente a 
la conectada con un debate obsoleto acerca de si estas prácticas deben ser incluidas o no en el 'catálogo institucional' de lo que 'es arte'. La hipótesis del impulso que estas prácticas suscitan socialmente y su diseminación, enraizada en los cambios no superficiales que generarían en sus participantes en primera instancia, y posteriormente en los sucesivos círculos concéntricos de sus públicos, es de suficiente calado como para no enredarnos nuevamente en debates taxonómicos que convienen a lo establecido.

Por último, señalemos un recorrido no desdeñable de varias décadas de estos modelos de creación, entroncados en cambios sociales de envergadura que inducen a una reflexión colectiva que no deja impasible al medio del arte. Estas prácticas suponen un cambio sustancial porque también la sociedad se embarca, desde ese momento rupturista, en nuevos recorridos sobre los que no pretenderán un retorno. Bien al contrario, preferirán marcar con claridad sus diferencias respecto a formatos que apreciarán como favorecedores de unas élites a las que una parte de la sociedad no está ya dispuesta a sostener, o al menos no mientras pueda. Las prácticas sociales en el arte, como hemos analizado, quedan por esta confluencia desde su origen politizadas, suponiendo este hecho en no pocas ocasiones un lastre para la lectura y comprensión de sus propuestas.

\section{REFERENCIAS}

Baudrillard, J. (1978). Cultura y simulacro. Barcelona: Kairos.

Bishop, C. (2006) The Social Turn: Collaboration and Its

Discontents, Artforum (Febrero, 2006) pp. 178-183

Blanco, P., (2005) Prácticas artísticas colaborativas. En Carrillo, Jesús, (coed.), Desacuerdos. Sobre arte, políticas y esfera pública en el Estado Español. Donostia: Arte y Pensamiento.

Borja-Villel, M. (2011) Hacia una nueva institucionalidad, Carta (2) pp. 1-2. Recuperado de https://www.museoreinasofia.es/ sites/default/files/revista/pdf/carta2.pdf

Cabrerizo, C. Klett, A. y García Bachiller, P. (2015) De alianzas anómalas a nuevos paisajes políticos. Madrid, Lavapiés y otras geografías de lo común, Revista de Estudios Urbanos y Ciencias Sociales Vol. 5(2) pp. 163-178

ColaBoraBora (s.f.) Sobre el procomún. Recuperado de: https:// www.colaborabora.org/colaborabora/sobre-el-procomun/

Fernández, O., Klett, A., López Mediero, Z., (2015) En medio de las cosas. Investigación indisciplinar, entre el espacio artístico, la academia y la ciudad, Transductores (3) pp. 223-233

Fontdevila, O. (2015) Comisariar arte colaborativo

¿Colaborativamente?, Transductores (3) pp. 211-222 
Fraser, A. (2016) L'1\% c'est moi. Barcelona, MUAC-MACBA.

Recuperado de: https://muac.unam.mx/assets/docs/P-105-

Folio_MUAC_048_Andrea_Fraser-Interiores-72dpi.pdf

Haraway, D., (1991a), Manifiesto Cyborg, Santa Cruz, University of California.

Haraway, D. (1991b) Ciencia, ciborgs y mujeres: la reinvención de la naturaleza. Madrid: Cátedra.

Imagina Madrid (2018). Recuperado de: https://www.imaginamadrid.es/es/imagina-madrid

Kester, G. (2013) Conversation pieces. Community and

Communication in Modern Art. University of California Press.

Klett, A., López Mediero, Z. (2021) Instituciones públicas y cambio social: el gobierno de las cosas pequeñas. Recuperado de: https://altermediae.org/instituciones-publicas-y-cambiosocial-el-gobierno-de-las-cosas-pequenas/\#

Lacy, S., (1995) (Ed.), Mapping the terrain. Seattle, Washington, Bay Press.

Lippard, L. y Chandler, J. (1968) La desmaterialización del arte. Nueva York: Art International, Vol. 12, (2).

Lippard, L. (1983). Trojan horses: Activist Art and Power. En Wallis, B. (Ed) Art After Modernism. Rethinking Representation. Nueva York: Ed.: I Boston.

Lord, C. y Meyer, R. (2013). Art and Queer Culture. London, Phaidon Press.

López Mediero, Z. (s.f). "Instituciones que aprenden. Hacia un prototipo de institución amateur". Recuperado de: https:// altermediae.org/instituciones-que-aprenden-hacia-un-prototipode-institucion-amateur/

Nochlin, L. (1971). "Why there have been no great women artists?" Art News. Recuperado el 12 de julio de 2017 de http:// www.artnews.com/2015/05/30/why- have-there-been-no-greatwomen-artists/

Pollock, G. (2017) Precariedad queer, la búsqueda de trabajo y la cuestión del personaje. En Cabello/Carceller y Segade, M., Borrador para una trama en curso, pp. 59-67. Madrid, CA2M ed. 
Ramos, L. (19 diciembre 2019) "La división entre artistas y ciudadanos es forzada", entrevista con Marcos García. El País. Recuperado de: https://elpais.com/ccaa/2019/12/16/ madrid/1576502467_457075.html

Toxic Lesbian (2010), "Cuentos que nunca cuentan". Recuperado de: https://www.toxiclesbian.org/proyectos-de-arte-publico-yciberfeminismo/cuentos-que-nunca-cuentan/

Toxic Lesbian (2018), “El Beso". Recuperado de: https://www. toxiclesbian.org/proyectos-de-arte-publico-y-ciberfeminismo/ el-beso/

\section{NOTAS}

1. El procomún, como señala ColaBoraBora-cooperativa de iniciativa social dedicada a facilitar procesos de colaboración centrados en las personas-, sería un modelo de gobernanza para el bien común formado por una gran diversidad de bienes naturales, culturales o sociales.

2. Toxic Lesbian -desde 2005, www.toxiclesbian.org- da nombre a los proyectos de arte público y ciberfeminismo desarrollados desde una perspectiva de género y/u orientación sexual, en colaboración con instituciones públicas y colectivos sociales, desde licencias copyleft, digitales y difundidos en la red.

3. Imagina Madrid es un programa de arte público y comunitario, coordinado por IntermediæMatadero, que explora nuevas formas de intervención en el espacio urbano a través de procesos de creación colectiva entre la ciudadanía y el tejido artístico.

4. Tales como el Centre for contemporary arts, Glasgow. La Tate Modern de Londres cuenta también en su colección con diversas muestras de artistas que son ya exponente del arte comunitario y procesual.

5. Instituciones en este sentido y de tamaño mediano sería IdeasCity New Museum, Nueva York. Las grandes instituciones como por ejemplo el Moca de Los Ángeles están igualmente habituadas a alojar y organizar procesos de prácticas sociales en el arte.

6. El término "ciberfeminismo" es amplio y culturalmente abarca a manifestaciones diversas. Definido inicialmente como un movimiento bajo la influencia de la tercera ola feminista, especialmente Donna Haraway fuente de inspiración con su "Manifiesto Cyborg" de 1987, reunió a artistas como las pioneras VNS Matrix con la idea de que el uso de las tecnologías implica una subversión de la identidad de género y puede apoyar el cambio en los roles sociales. Su implicación política fundamental se implementa en la red y deriva posteriormente en múltiples comprensiones del fenómeno desde perspectiva feminista. El empleo de tecnologías para el diseño de obras de arte se concibe como un campo estratégico y político.

7. Disponible en https://toxiclesbian.org/topete/El_Beso.html 